\title{
Evaluation of the Efficacy of Spa Therapy on Pain and Quality of Life in Patients With Chronic Mechanical Neck Pain
}

\author{
Aycan TÜREL, ${ }^{1}$ Özlem SOLAK, ${ }^{2}$ Ümit DÜNDAR, ${ }^{2}$ Hasan TOKTAŞ, ${ }^{2}$ \\ Ümit Seçil DEMİRDAL, ${ }^{3}$ Volkan SUBAŞI, ${ }^{4}$ Vural KAVUNCU ${ }^{2}$ \\ ${ }^{1}$ Department of Physical Medicine and Rehabilitation, Afyonkarahisar State Hospital, Afyonkarahisar, Turkey \\ ${ }^{2}$ Department of Physical Medicine and Rehabilitation, Medical Faculty of Afyon Kocatepe University, Afyonkarahisar, Turkey \\ ${ }^{3}$ Department of Physical Medicine and Rehabilitation, Medical Faculty of İzmir Katip Çelebi University, İzmir, Turkey \\ ${ }^{4}$ Department of Physical Medicine and Rehabilitation, Özgür Yaşam Physical Medicine and Rehabilitation Center, Mersin, Turkey
}

\begin{abstract}
Objectives: This study aims to evaluate the efficacy of spa therapy on pain and the quality of life in patients with chronic mechanical neck pain.

Patients and methods: Seventy patients who applied to our outpatient clinic with chronic mechanical neck pain lasting for 12 weeks were included in the study. Patients were randomized either to spa therapy group (7 males, 28 females; mean age $43.08 \pm 9.76$ years; range 26 to 66 years) or to exercise therapy group ( 5 males, 30 females; $46.45 \pm 9.65$ years; range 27 to 65 years). Spa therapy group received a total of 15 sessions of thermal water, mud therapy, and classic massage to cervical region. Both exercise and spa therapy groups performed home exercise program once a day for 15 days. All the patients were evaluated before treatment, at the first week and at the third month after treatment, a total of three times. In each control; visual analog scale, global assessment of the patient (Patient's Global Assessment and Physician's Global Assessment), Neck Pain Disability Scale, and Nottingham Health Profile were assessed.

Results: When the measurements at first week were compared to baseline, significant improvements were observed in all the parameters in both groups. However, the decreases in visual analog scale and Neck Pain Disability Scale at the first week after treatment were more significant in spa therapy group compared to exercise therapy group. We observed no statistically significant difference in all the parameters between two groups when the measurements at the third month were compared to baseline.

Conclusion: The combination of spa therapy with exercise therapy is superior to exercise therapy alone in decreasing pain and improving functional capacity in the early period after treatment.

Keywords: Mechanical neck pain; mud therapy; spa therapy.
\end{abstract}

Currently, mechanical neck pain is the second most common type of pain after low back pain in chronic pain classifications. ${ }^{1-3}$ At any given time, approximately 10 to $20 \%$ of the population reports neck problems. Because most neck pain has no specific, identifiable cause, it is diagnosed as mechanical neck pain. ${ }^{4}$

While symptoms of neck pain may spontaneously resolve within a few weeks, 30\% of the symptoms may persist as chronic neck pain. Chronic neck pain increases the cost of treatment and decreases work capacity. Also, neck pain results in as much lost work days as low back pain in industrial work areas. ${ }^{5}$ Thus, planning for effective treatment is considerably important. The goals of treatment in a patient with neck pain should be to reduce pain, restore mobility of cervical joints, and prevent disability in long-term. ${ }^{6}$ Common treatment consists of drugs, massage and other manual treatments, physiotherapy and exercise, local and epidural injections, and patient education. ${ }^{7}$ 
Spa therapy, also known as balneotherapy or thermal therapy, has been widely used for the treatment of several musculoskeletal disorders since the $18^{\text {th }}$ century in Europe. ${ }^{8}$ During spa therapy, patients are treated with thermal mineral water and receive many other treatment modalities including massage, electrotherapy, and exercise. ${ }^{9}$

There are several studies reporting positive effects of spa therapy in patients with osteoarthritis in the literature. These studies have targeted specific joints such as knee and vertebral osteoarthritis. ${ }^{10}$ Recent studies have reported effects of spa therapy on chronic painful conditions including low back pain and rheumatoid arthritis. ${ }^{11}$

To our knowledge, the only study in the literature to demonstrate the efficacy of spa therapy in patients with chronic neck pain is of Forestier et al. ${ }^{12}$ who have compared the effects of spa therapy and electromagnetic field therapy in patients with chronic neck pain. In that study, no difference has been shown between spa therapy and electromagnetic field therapy except for the $20 \%$ decreased pain during the pain assessment at the sixth month evaluation.

In light of these findings, in this study, we aimed to evaluate the efficacy of spa therapy on pain and quality of life in patients with chronic mechanical neck pain.

\section{PATIENTS AND METHODS}

The study population was chosen among patients with chronic neck pain who attended the Outpatient Clinic of Department of Physical Medicine and Rehabilitation of Medical Faculty of Afyon Kocatepe University between August 2007 and July 2008. All patients' informed

Table 1. Study inclusion criteria

Patients with mechanical neck pain lasting for more than 12 weeks

Patients with a visual analog scale score of 5 or above

Patients who did not receive thermal therapy for neck pain within less than one year

Patients who agree to discontinue their medical therapy for neck pain at least one week before initiating treatment

Patients with a normal $\mathrm{C}$-reactive protein value signed consent was obtained. The study was approved by our Institutional Research Ethics Committee. A total of 70 patients were enrolled in the study. Patients were randomized either to spa therapy group (7 males, 28 females; mean age $43.08 \pm 9.76$ years; range 26 to 66 years) or exercise therapy group ( 5 males, 30 females; $46.45 \pm 9.65$ years; range 27 to 65 years) by using the table of random numbers. Study inclusion criteria and exclusion criteria are shown in Table 1 and Table 2, respectively.

All patients' age, sex, body mass index, occupation, and duration of neck pain were recorded. Therapy-related changes in the severity of neck pain were evaluated by visual analog scale (VAS), Patient's Global Assessment (PatientVAS), and Physician's Global Assessment (DrVAS). Pain, and patient's and physician's global assessments were evaluated with $10 \mathrm{~cm}$ VAS, where 0 indicates no pain or best, whereas 10 indicates intractable pain or worst.

Changes in neck pain and disability were assessed by using Neck Pain Disability Scale (NPDS). NPDS is a 20-item questionnaire developed by using the Million visual analog scale as a template. The items explore pain intensity; its interference with vocational, recreational, social and functional aspects of living, as well as the presence and extent of associated emotional factors. Each item has a $10 \mathrm{~cm}$ VAS. Scoring of each item varies along a continuous scale from 0 to $5 .^{13}$ Scores above 23 indicate clinically significant neck pain and the higher the score, the greater the degree of pain and disability. ${ }^{14}$

Patients' quality of life was assessed by using Nottingham Health Profile (NHP). NHP assesses physical, social, and emotional health with 38 items answered 'yes' or 'no'. The 'weighted score' of the related question was given for each 'yes' and 0 point for each 'no'. The overall score

Table 2. Study exclusion criteria

Presence of an unregulated cardiac, pulmonary, kidney or thyroid gland condition or diabetes mellitus

Presence of an inflammatory rheumatic condition

Presence of magnetic resonance imaging confirmed cervical herniation requiring surgery or causing neurological deficit Presence of spondylolisthesis

Patients with structural disorders such as scoliosis

Patients who are allergic to oils used in the massage therapy 
Table 3. Comparison of patients' demographic data

\begin{tabular}{|c|c|c|c|c|c|c|c|c|c|}
\hline & \multicolumn{4}{|c|}{$\begin{array}{l}\text { Spa therapy group } \\
\left(25^{\text {th }}-75^{\text {th }}\right) \text { percentiles }\end{array}$} & \multicolumn{4}{|c|}{$\begin{array}{l}\text { Exercise therapy group } \\
\left(25^{\text {th }}-75^{\text {th }}\right) \text { percentiles }\end{array}$} & \multirow[b]{2}{*}{$p$} \\
\hline & $\mathrm{n}$ & Mean \pm SD & Median & Min.-Max. & $\mathrm{n}$ & Mean \pm SD & Median & Min.-Max. & \\
\hline \multicolumn{10}{|l|}{ Gender } \\
\hline Female & 28 & & & & 30 & & & & $0.751^{*}$ \\
\hline Male & 7 & & & & 5 & & & & \\
\hline Mean age (years) & & $43.08 \pm 9.76$ & 43 & 34-51 & & $46.45 \pm 9.65$ & 47 & $38-53$ & $0.151^{* *}$ \\
\hline Mean body mass index & & $28.08 \pm 4.41$ & 28.04 & $24.22-30.80$ & & $30.26 \pm 4.74$ & 30.11 & $27.89-32.89$ & $0.051^{* * *}$ \\
\hline Duration of disease (months) & & $17.45 \pm 9.62$ & 12 & $12-24$ & & - & - & - & $0.795^{* * * *}$ \\
\hline
\end{tabular}

was calculated separately for each parameter and then NHP total score was obtained from the sum of the scores of these six parameters. ${ }^{15}$

Patients allocated in the spa therapy group had total body bath with thermal water including the cervical region, and mud therapy and massage without massage oil to cervical region in the Cure Center of Department of Physical Medicine and Rehabilitation. All those therapies were given once daily for five days a week, for a total of 15 sessions. Additionally, they received the same home exercise program as given to the exercise therapy group.

The exercise therapy group was given a home exercise program. These exercises were instructed to the patients in both groups by the same physiotherapist including one practice session and a descriptive exercise brochure was provided. Exercises included isometric neck exercises and stretching exercises for muscles of the back and neck. Stretching exercises were applied on the scalene, upper part of trapezius, pectoralis minor muscles, interspinous muscles, and ligamentum nuchae. Patients were instructed to perform the exercise program once daily as one session for 15 days and to repeat each exercise 10 times during one session. Patients were contacted by phone every 3-4 days to assess their compliance with the exercise program and by this way, completion of the exercise program was achieved. Patients were evaluated before treatment, at the first week after treatment and at the third month after treatment, three times in total.

\section{Statistical analysis}

For statistical evaluation of the study findings, IBM SPSS Statistics version 21.0 software program (IBM Corporation, Armonk, NY, USA) was used. For descriptive statistics, numerical data were expressed as mean \pm standard deviation and median

Table 4. Comparison of mean pretreatment measurements of follow-up parameters

\begin{tabular}{|c|c|c|c|c|c|c|c|}
\hline \multirow[b]{2}{*}{ Follow-up parameters } & \multicolumn{3}{|c|}{$\begin{array}{l}\text { Spa therapy group } \\
\left(25^{\text {th }}-75^{\text {th }}\right) \text { percentiles }\end{array}$} & \multicolumn{3}{|c|}{$\begin{array}{l}\text { Exercise therapy group } \\
\left(25^{\text {th }}-75^{\text {th }}\right) \text { percentiles }\end{array}$} & \multirow[b]{2}{*}{$p$} \\
\hline & Mean \pm SD & Median & Min.-Max. & Mean \pm SD & Median & Min.-Max. & \\
\hline VAS & $58.9 \pm 8.0$ & 60 & $50-60$ & $56.0 \pm 7.7$ & 50 & $50-60$ & $0.095^{*}$ \\
\hline PatientVAS & $44.0 \pm 24.6$ & 50 & $20-60$ & $42.6 \pm 25.4$ & 50 & $20-60$ & $0.707^{*}$ \\
\hline DrVAS & $45.1 \pm 22.1$ & 50 & $30-60$ & $41.4 \pm 20.7$ & 40 & $820-60$ & $0.425^{*}$ \\
\hline \multicolumn{8}{|l|}{ Nottingham Health Profile } \\
\hline Energy & $58.1 \pm 30.5$ & 39.20 & $39.20-76$ & $59.2 \pm 38.3$ & 76 & $39.20-100$ & $0.733^{*}$ \\
\hline Pain & $59.8 \pm 20.8$ & 59.78 & $42.35-79.52$ & $59.1 \pm 30.6$ & 62.21 & $29.44-80.26$ & $0.851^{*}$ \\
\hline Emotional reaction & $39.2 \pm 30.3$ & 35.72 & $9.76-63.22$ & $44.8 \pm 29.3$ & 49.58 & $16.21-69.80$ & $0.356^{*}$ \\
\hline Sleep & $48.4 \pm 31.0$ & 48.96 & $16.10-77.63$ & $47.3 \pm 28.6$ & 55.93 & $16.10-77.63$ & $0.892^{*}$ \\
\hline Social isolation & $22.6 \pm 29.9$ & 0 & $0-42.66$ & $26.5 \pm 31.1$ & 20.13 & $0-48.49$ & $0.551^{*}$ \\
\hline Physical mobility & $32.6 \pm 18.2$ & 31.29 & $21.77-43.27$ & $29.7 \pm 19.8$ & 30.66 & $19.87-41.86$ & $0.538^{* * *}$ \\
\hline Neck Pain and Disability Scale & $47.2 \pm 2.0$ & 49 & $34-64$ & $43.0 \pm 18.7$ & 40 & 25-61 & $0.374 * *$ \\
\hline
\end{tabular}

SD: Standard deviation; Min.: Minimum; Max.: Maximum; VAS: Visual analog scale; PatientVAS: Patient's Global Assessment; DrVAS: Physician's Global Assessment; * Mann Whitney U test; ** Independent Samples t-test. 


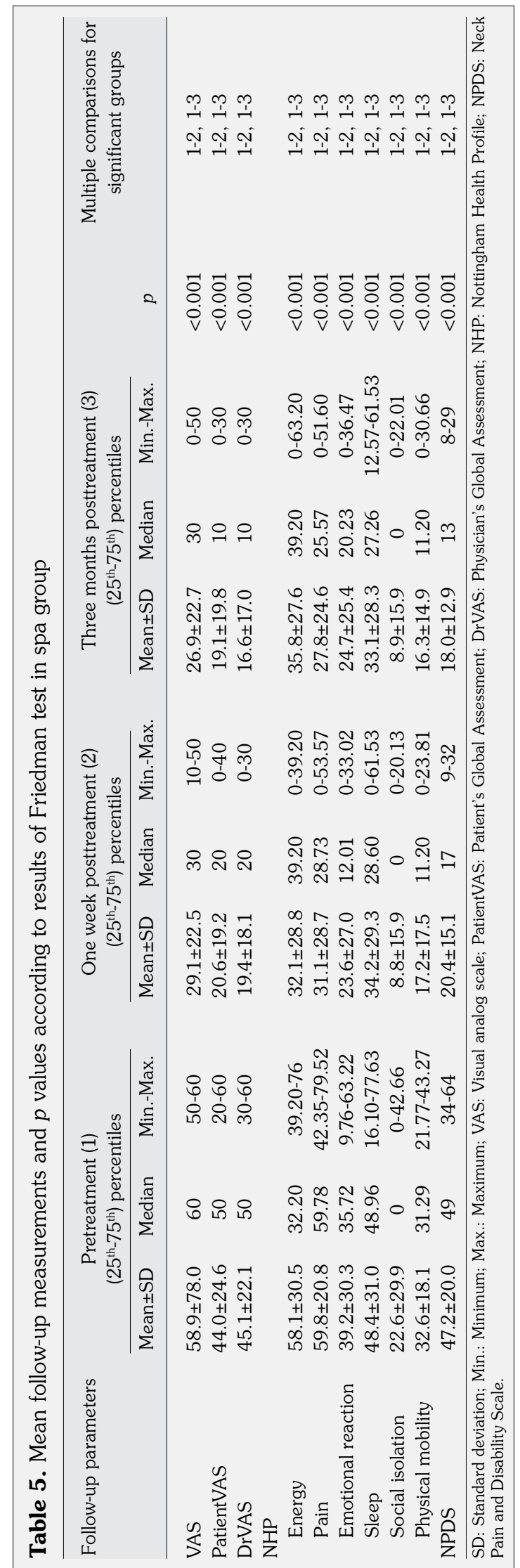

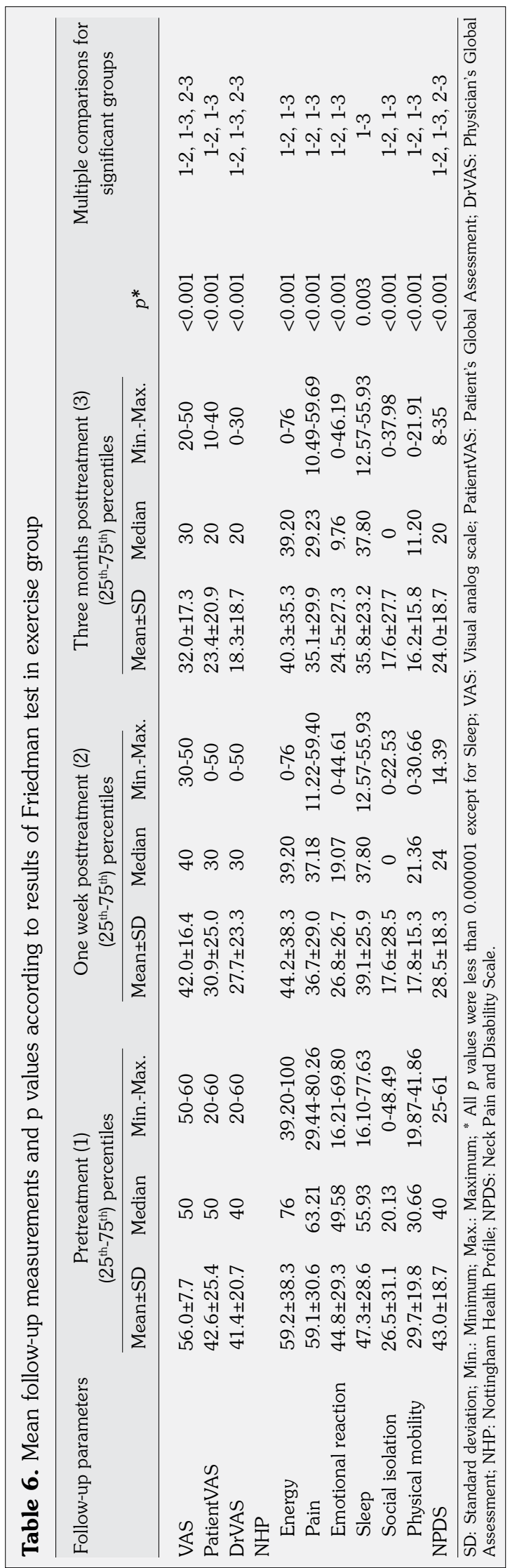


$\left(25^{\text {th }}-75^{\text {th }}\right.$ percentiles), categorical variables as numbers and percentages. Yates Chi-square test was used for comparing categorical data between groups. Independent Samples t-test was used for comparing normally distributed continuous variables. Mann-Whitney U test was used for comparing non-normally distributed continuous variables. In addition, within-group changes were assessed by using Friedman test for repetitive measurements of non-normally continuous data for each group. Shapiro-Wilk test was used to determine the normality. A $p$ value less than 0.05 was considered statistically significant.

\section{RESULTS}

Groups were similar with respect to sex distribution and mean ages $(p=0.751, p=0.151$, respectively). Demographic characteristics of patients are depicted in Table 3.

Mean pre-treatment values of parameters used for follow-up of patients are depicted in Table 4. There was no statistically significant difference between two groups at baseline.

In the spa therapy group, a significant improvement was found in NHP subscales during assessments at the first week and three months after completion of therapy (for all subscales $\mathrm{p}<0.001)$.

Mean NPDS values were 20.42 \pm 15.12 and $17.97 \pm 12.86$ at the first week and three months after treatment in the spa therapy group, respectively. A statistically significant improvement was detected in mean NPDS values at both assessments $(p<0.001)$.

A significant improvement was found in VAS, PatientVAS, and DrVAS values in the exercise therapy group at one week and three months posttreatment $(p<0.001, p<0.001$, and $p<0.001$, respectively).

A significant improvement was demonstrated in NHP subscales during assessments at one week and three months after completion of therapy in the exercise therapy group $(p=0.003$ for sleep; $p<0.001$ for all the other subscales).

Mean NPDS values of $28.54 \pm 18.30$ and $23.97 \pm 18.72$ were detected at one week and three months posttreatment in the exercise therapy group, respectively. A statistically significant improvement was found in mean NPDS values at both assessments $(p<0.001)$.

Tables 5 and 6 show the mean follow-up measurements and $\mathrm{p}$ values according to the results of Friedman test in the spa therapy and exercise therapy groups, respectively.

Statistically significant improvements were observed in all parameters assessed at both one week and three months after completion of treatment in spa therapy and exercise therapy groups. Then, mean changes achieved at one week and three months posttreatment were compared in both groups to determine which group had greater improvement.

Statistically significantly greater decrease in VAS value was found in the spa therapy group when mean change score obtained from VAS values in the spa therapy group was compared to the mean change score in the exercise therapy group $(p<0.001)$.

Comparison of mean change score in the NPDS value of the spa therapy group at one week to the mean change score of the exercise therapy group showed that the decrease was statistically significantly greater in spa therapy group ( $p=0.001)$.

A comparison of mean change scores in the follow-up parameters measured at one week posttreatment based on pretreatment values in both groups is shown in Table 7 .

There was statistical difference between groups when mean change score of NPDS value in spa therapy group at three months posttreatment was compared to the mean change score in the exercise therapy group $(p=0.024)$ (Table 8).

\section{DISCUSSION}

In our study, we observed significantly greater reductions in pain and disability level of patients with chronic mechanical neck pain with spa therapy in the early period of the treatment. Spa therapy was consisting of thermal, mud, and massage therapies applied to neck region.

Among musculoskeletal disorders, neck pain is the second most common problem after 
Table 7. Comparison of mean change scores in follow-up parameters measured at one week posttreatment based on pretreatment values in both groups

\begin{tabular}{|c|c|c|c|c|c|c|c|}
\hline \multirow[b]{2}{*}{ Follow-up parameters } & \multicolumn{3}{|c|}{$\begin{array}{l}\text { Spa therapy group } \\
\left(25^{\text {th }}-75^{\text {th }}\right) \text { percentiles }\end{array}$} & \multicolumn{3}{|c|}{$\begin{array}{l}\text { Exercise therapy group } \\
\left(25^{\text {th }}-75^{\text {th }}\right) \text { percentiles }\end{array}$} & \multirow[b]{2}{*}{$p^{*}$} \\
\hline & Mean \pm SD & Median & Min.-Max. & Mean \pm SD & Median & Min.-Max. & \\
\hline VAS & $-29.7 \pm 18.9$ & -30 & $-50--10$ & $-14 \pm 13.8$ & -10 & $-20--10$ & 0.001 \\
\hline PatientVAS & $-23.4 \pm 25.8$ & -10 & $-40-0$ & $-11.7 \pm 14.7$ & -20 & $-50-0$ & 0.225 \\
\hline DrVAS & $-25.7 \pm 21.9$ & -20 & $-40--10$ & $-13.7 \pm 14.2$ & -10 & $-20-0$ & 0.022 \\
\hline \multicolumn{8}{|l|}{ Nottingham Health Profile } \\
\hline Energy & $-26.0 \pm 33.0$ & 0 & $-39.20-0$ & $-15.0 \pm 18.7$ & 0 & $-36.80-0$ & 0.210 \\
\hline Pain & $-28.7 \pm 29.1$ & -22.16 & $-51.53-0$ & $-22.4 \pm 21.8$ & -19.45 & $-40.31-0$ & 0.586 \\
\hline Emotional reaction & $-15.7 \pm 20.6$ & -9.78 & $-27.94-0$ & $-18.1 \pm 22.9$ & -9.76 & $-25.52-0$ & 0.891 \\
\hline Sleep & $-14.2 \pm 27.5$ & -12.57 & $-28.67-0$ & $-8.2 \pm 20.1$ & 0 & $-12.57-0$ & 0.119 \\
\hline Social isolation & $-13.8 \pm 22.0$ & 0 & $-22.53-0$ & $-8.9 \pm 14.3$ & 0 & $-19.36-0$ & 0.634 \\
\hline Physical mobility & $-15.4 \pm 16.6$ & -11.20 & $-31.29-0$ & $-11.9 \pm 15.2$ & -9.93 & $-20.84-0$ & 0.304 \\
\hline Neck Pain and Disability Scale & $-26.7 \pm 18.9$ & -22 & $-37--13$ & $-14.5 \pm 8.7$ & -12 & $-19--9$ & 0.001 \\
\hline
\end{tabular}

low back pain in the general population. ${ }^{16}$ The goals of therapy in chronic neck pain include decreasing pain and disability, and improving endurance. ${ }^{17}$

There are several conservative treatment methods applied for this purpose. A randomized, double-blind, placebo-controlled study of low-level laser therapy in 90 subjects with chronic neck pain was conducted with the aim of determining the efficacy of $300 \mathrm{~mW}, 830 \mathrm{~nm}$ laser in the management of chronic neck pain. Significant improvements were seen in the active group compared to placebo. ${ }^{18}$
Exercise therapy has well-known positive effects on the muscular and cardiovascular system, such as increasing muscular strength and coordination as well as aerobic capacity. Furthermore, exercise therapy is known to be a powerful instrument in the treatment of musculoskeletal chronic pain. ${ }^{11}$

Ylinen et al. ${ }^{19}$ compared the effects of manual therapy and stretching exercise on neck pain and disability. Both stretching exercise and manual therapy considerably decreased neck pain and disability in females with non-specific neck pain. The difference in

Table 8. Comparison of mean change scores in follow-up parameters measured at three months posttreatment based on pretreatment values in both groups

\begin{tabular}{|c|c|c|c|c|c|c|c|}
\hline \multirow[b]{2}{*}{ Follow-up parameters } & \multicolumn{3}{|c|}{$\begin{array}{l}\text { Spa therapy group } \\
\left(25^{\text {th }}-75^{\text {th }}\right) \text { percentiles }\end{array}$} & \multicolumn{3}{|c|}{$\begin{array}{l}\text { Exercise therapy group } \\
\left(25^{\text {th }}-75^{\text {th }}\right) \text { percentiles }\end{array}$} & \multirow[b]{2}{*}{$p^{*}$} \\
\hline & Mean \pm SD & Median & Min.-Max. & Mean \pm SD & Median & Min.-Max. & \\
\hline VAS & $-32 \pm 18.6$ & -30 & $-50--20$ & $-24 \pm 16.5$ & -30 & $-30--10$ & 0.096 \\
\hline PatientVAS & $-24.9 \pm 31.3$ & -20 & $-50-0$ & $-19.1 \pm 16.3$ & -20 & $-30-0$ & 0.585 \\
\hline DrVAS & $-28.6 \pm 24.5$ & -20 & $-50--10$ & $-23.1 \pm 16.0$ & -20 & $-40--10$ & 0.387 \\
\hline \multicolumn{8}{|l|}{ Nottingham Health Profile } \\
\hline Energy & $-22.3 \pm 30.5$ & 0 & $-39.20-0$ & $-18.9 \pm 21.4$ & 0 & $-39.20-0$ & 0.919 \\
\hline Pain & $-32.0 \pm 26.1$ & -29.35 & $-49.46--9.99$ & $-24.0 \pm 21.8$ & -20.86 & $-44.26-0$ & 0.212 \\
\hline Emotional reaction & $-14.5 \pm 19.6$ & -10.69 & $-36.43-0$ & $-20.3 \pm 24.1$ & -13.99 & $-32.74-0$ & 0.414 \\
\hline Sleep & $-15.2 \pm 27.3$ & -12.57 & $-39.83-0$ & $-11.5 \pm 21.5$ & 0 & $-22.37-0$ & 0.241 \\
\hline Social isolation & $-13.8 \pm 23.0$ & 0 & $-22.01-0$ & $-8.9 \pm 14.7$ & 0 & $-19.36-0$ & 0.722 \\
\hline Physical mobility & $-16.2 \pm 16.7$ & -20.50 & $-30.60-0$ & $-13.5 \pm 15.2$ & -11.2 & $-21.77-0$ & 0.446 \\
\hline Neck Pain and Disability Scale & $-29.2 \pm 19.8$ & -27 & $-36--15$ & $-19.1 \pm 13.6$ & -17 & $-26--11$ & 0.024 \\
\hline
\end{tabular}

SD: Standard deviation; Min.: Minimum; Max.: Maximum; VAS: Visual analog scale; * Mann-Whitney U test; PatientVAS: Patient's Global Assessment; DrVAS: Physician's Global Assessment. 
effectiveness between the two treatments was minor.

To our knowledge, the only study in the literature to demonstrate the efficacy of spa therapy in patients with chronic neck pain was conducted by Forestier et al. ${ }^{12}$ who compared the effects of spa therapy and electromagnetic field therapy in patients with chronic neck pain. In this study, $20 \%$ or greater decrease in pain from baseline values as measured by VAS was considered as improvement. In the same study, more patients in the electromagnetic field therapy group showed improvement compared to spa therapy group and no difference was found between two groups except for the $20 \%$ decrease in VAS values at sixth month.

In our study, a significant reduction was seen in VAS values at one week and three months with spa therapy and exercise therapy when groups were evaluated within themselves. However, the reduction in VAS value obtained at one week after treatment in the spa therapy group was significantly superior compared to the control group. In the view of the results obtained from VAS values, we can say that patients experienced reduced pain with both spa therapy and exercise therapy and this was much more evident with spa therapy in the early posttreatment period.

Our study demonstrated significant improvements in patient's and physician's global assessments at one week and three months after treatment in spa therapy and exercise therapy groups. However, there was no statistically significant difference between two groups. Consistent with our study findings, Wigler et al. ${ }^{20}$ observed significant improvements in patient's and physician's global assessments over 16 weeks in patients with gonarthrosis who were given spa therapy for two weeks.

Furthermore, we observed significant reductions in neck pain and disability level evaluated by NPDS with spa therapy and exercise therapy at one week and three months after treatment. However, the reduction in NPDS value achieved at the first week after treatment was better in the spa therapy group compared to the exercise therapy group. Based on the results obtained from NPDS values, we might consider that patients experienced reduced neck pain and disability with both spa therapy and exercise therapy and this was much more evident with spa therapy in the early posttreatment period.

In our study, an active therapeutic exercise treatment including isometric strength exercises for the neck and neck-back stretching exercises was given to spa therapy group in addition to thermal, mud, and massage therapies. The same exercises were given to the exercise therapy group as home exercise program. Consistent with literature, we demonstrated considerably improved pain, functional capacity and quality of life scales during follow-up at one week and three months in both groups. ${ }^{4,17,21}$ However, improved pain and functional capacity were statistically significantly superior in spa therapy group at the first week posttreatment compared to the exercise therapy group. This supports the argument that when combined with exercise, spa therapy might achieve more successful results in the early period.

The main limitation of spa therapy related studies were lack of a control population. It is very difficult to maintain the blindness factor, since the physicochemical properties (color, odor, feel by touch) of mineral water significantly differ from tap (control) water and can easily be discerned by patients. $^{22}$

Fioravanti et al. $^{23}$ assessed both the shortand long-term effectiveness of spa therapy in patients with primary knee OA. In this study, patients were randomized as a spa therapy group and control group, and continued regular routine ambulatory care (exercise, nonsteroidal antiinflammatory drugs, and/or analgesics). Authors observed a significant improvement in all evaluated parameters at the end of the cycle of spa therapy, whereas no significant differences were noted in the control group.

In another study, Karagülle et al. ${ }^{24}$ compared spa therapy and drug therapy differences in patients with severe knee osteoarthritis. Twenty patients were randomized into spa and drug therapy groups. Spa group $(n=10)$ stayed at a hotel for a 10 day spa therapy course. Drug therapy group $(n=10)$ stayed at home and followed their individually prescribed drug therapy (nonsteroidal antiinflammatory drugs 
and paracetamol). Consistent with our study, Karagülle et al. $^{24}$ demonstrated that a 10 day course of spa therapy may be beneficial in short and medium term by reducing pain and improving functional status.

In the study by Forestier et al., ${ }^{25}$ the only study in the literature to show the efficacy of spa therapy in patients with chronic neck pain, a total of 86 patients with chronic mechanical neck pain were randomized to receive spa therapy $(n=44)$ or intermittent electromagnetic field therapy $(n=42)$. In the first part of their study, researchers. ${ }^{25}$ compared the efficacy of spa therapy with electromagnetic field therapy in patients with chronic neck pain and then evaluated the medico-economic aspects in the second part. As a result, they showed that electromagnetic field therapy and spa therapy provided cost-effective medical benefits compared to conventional therapy in the treatment of chronic neck pain.

Several aspects of spa therapy can be distinguished as potentially therapeutically effective. These are (i) natural remedies such as mud and thermal water, (ii) additional therapies such as massages and electrotherapy, (iii) living in a resort environment, and (iv) having a respite from work. ${ }^{11}$

The limitations of our study is that the follow-up period was relatively short, so we were unable to assess the effects of spa therapy in longer durations. In conclusion, combined use of thermal, mud, massage and exercise therapies, also known as spa therapy, results in a greater reduction in pain and improved functional capacity in the early period compared to exercise therapy alone in patients with chronic mechanical neck pain. Spa therapy contributes positively to functional capacity of the neck in long-term period. Thus, we conclude that spa therapy should be considered as a treatment option in patients with chronic mechanical neck pain, but our findings should be supported with further studies with longer follow-up period and larger sample size.

\section{Declaration of conflicting interests}

The authors declared no conflicts of interest with respect to the authorship and/or publication of this article.

\section{Funding}

The authors received no financial support for the research and/or authorship of this article.

\section{REFERENCES}

1. Biçer A, Yazıcı A, Yazııı K, Tot Ş, Erdoğan C. Kronik mekanik bel ve boyun ağrılı hastaların özürlülük, anksiyete ve depresyon açısından karşılaştırılması. Türk Fiz Tip Rehab Derg 2004;50:55-60.

2. DePalma J M , Slipman W C. Treatment of common neck problems. In: Braddom LR, editor. Physical Medicine and Rehabilitation. 3rd ed. Philadelphia: Elseiver; 2007. p. 797- 824.

3. Vernon H, Humphreys K, Hagino C. Chronic mechanical neck pain in adults treated by manual therapy: a systematic review of change scores in randomized clinical trials. J Manipulative Physiol Ther 2007;30:215-27.

4. Bronfort G, Evans R, Nelson B, Aker PD, Goldsmith $\mathrm{CH}$, Vernon $\mathrm{H}$. A randomized clinical trial of exercise and spinal manipulation for patients with chronic neck pain. Spine (Phila Pa 1976) 2001;26:788-97.

5. Ylldız M, Tuna $\mathrm{H}$, Kokino $\mathrm{S}$. Türk kronik boyun ağrılı olgularda spinal mobilite, ağrı ve özürlülük ilişkisinin değerlendirilmesi. Türk Fiz Tip Rehab Derg 2005;51:127-30.

6. Aydın R. Medikal tedavi. In: Gökçe-Kutsal Y, editör. Boyun ağrısı. Ankara: Güneş Kitapevi; 2002. s. 79-95.

7. Irnich D, Behrens N, Molzen H, König A, Gleditsch $\mathrm{J}$, Krauss $\mathrm{M}$, et al. Randomised trial of acupuncture compared with conventional massage and "sham" laser acupuncture for treatment of chronic neck pain. BMJ 2001;322:1574-8.

8. Sukenik S, Flusser D, Abu-Shakra M. The role of spa therapy in various rheumatic diseases. Rheum Dis Clin North Am 1999;25:883-97.

9. Bender T, Karagülle Z, Bálint GP, Gutenbrunner C, Bálint PV, Sukenik S. Hydrotherapy, balneotherapy, and spa treatment in pain management. Rheumatol Int 2005;25:220-4.

10. Cimbiz A, Bayazit V, Hallaceli $\mathrm{H}$, Cavlak U. The effect of combined therapy (spa and physical therapy) on pain in various chronic diseases. Complement Ther Med 2005;13:244-50.

11. Strauss-Blasche G, Ekmekcioglu C, Vacariu G, Melchart H, Fialka-Moser V, Marktl W. Contribution of individual spa therapies in the treatment of chronic pain. Clin J Pain 2002;18:302-9.

12. Forestier R, Françon A, Saint-Arromand F, Bertolino C, Guillemot A, Graber-Duvernay B, et al. Are SPA therapy and pulsed electromagnetic field therapy effective for chronic neck pain? Randomised clinical trial First part: clinical evaluation. Ann Readapt Med Phys 2007;50:140-7. 
13. Bicer A, Yazici A, Camdeviren H, Erdogan C. Assessment of pain and disability in patients with chronic neck pain: reliability and construct validity of the Turkish version of the neck pain and disability scale. Disabil Rehabil 2004;26:959-62.

14. Wheeler AH, Goolkasian P, Gretz SS. Botulinum toxin A for the treatment of chronic neck pain. Pain 2001;94:255-60.

15. Yurtkuran M, Yurtkuran M, Alp A, Nasircilar A, Bingöl U, Altan L, et al. Balneotherapy and tap water therapy in the treatment of knee osteoarthritis. Rheumatol Int 2006;27:19-27.

16. Vernon H, Humphreys BK, Hagino C. The outcome of control groups in clinical trials of conservative treatments for chronic mechanical neck pain: a systematic review. BMC Musculoskelet Disord 2006;7:58.

17. Borman P, Keskin D, Ekici B, Bodur H. The efficacy of intermittent cervical traction in patents with chronic neck pain. Clin Rheumatol 2008;27:1249-53.

18. Chow RT, Heller GZ, Barnsley L. The effect of 300 $\mathrm{mW}, 830 \mathrm{~nm}$ laser on chronic neck pain: a doubleblind, randomized, placebo-controlled study. Pain 2006;124:201-10.

19. Ylinen J, Kautiainen $H$, Wirén K, Häkkinen A. Stretching exercises vs manual therapy in treatment of chronic neck pain: a randomized, controlled cross- over trial. J Rehabil Med 2007;39:126-32.

20. Wigler I, Elkayam O, Paran D, Yaron M. Spa therapy for gonarthrosis: a prospective study. Rheumatol Int 1995;15:65-8.

21. Philadelphia Panel. Philadelphia Panel evidencebased clinical practice guidelines on selected rehabilitation interventions for neck pain. Phys Ther 2001;81:1701-17.

22. Gaál J, Varga J, Szekanecz Z, Kurkó J, Ficzere A, Bodolay $\mathrm{E}$, et al. Balneotherapy in elderly patients: effect on pain from degenerative knee and spine conditions and on quality of life. Isr Med Assoc $\mathrm{J}$ 2008;10:365-9.

23. Fioravanti A, Iacoponi F, Bellisai B, Cantarini L, Galeazzi M. Short- and long-term effects of spa therapy in knee osteoarthritis. Am J Phys Med Rehabil 2010;89:125-32.

24. Karagülle $M$, Karagülle $M Z$, Karagülle $O$, Dönmez A, Turan M. A 10-day course of SPA therapy is beneficial for people with severe knee osteoarthritis. A 24-week randomised, controlled pilot study. Clin Rheumatol 2007;26:2063-71.

25. Forestier R, Françon A, Saint Arroman F, Bertolino C, Graber-Duvernay B, Guillemot A, et al. Are SPA therapy and pulsed electromagnetic field therapy effective for chronic neck pain? Randomised clinical trial. Second part: medicoeconomic approach. Ann Readapt Med Phys 2007;50:148-53. 